\title{
The Effect of the Japan 2011 Disaster on Nuclear and Alternative Energy Stocks Worldwide: An Event Study
}

Robert Ferstl, Oesterreichische Nationalbank(OeNB), Austria, E-mail: rferstl@gmx.net

Sebastian Utz, Department of Finance, University of Regensburg, Germany, E-mail: sebastian.utz@ur.de

Maximilian Wimmer, Department of Finance, University of Regensburg, Germany, E-mail: maximilian.wimmer@ur.de

\begin{abstract}
This event study investigates the impact of the Japanese nuclear disaster in Fukushima-Daiichi on the daily stock prices of French, German, Japanese, and U.S. nuclear utility and alternative energy firms. Hypotheses regarding the (cumulative) abnormal returns based on a three-factor model are analyzed through joint tests by multivariate regression models and bootstrapping. Our results show significant abnormal returns for Japanese nuclear utility firms during the one-week event window and the subsequent four-week post-event window. Furthermore, while French and German nuclear utility and alternative energy stocks exhibit significant abnormal returns during the event window, we cannot confirm abnormal returns for U.S. stocks.
\end{abstract}

JEL-classification: G14, G12, G15

Keywords: event study, nuclear accidents, Fukushima-Daïchi, Fama-French model, bootstrap

Manuscript received May 23, 2011, accepted by Engelbert Dockner (Finance) March 3, 2012.

\section{Introduction}

On March 11, 2011, an earthquake and ensuing tsunami devastated extensive parts of the northeastern Japanese coastline. Besides the natural catastrophe, the concern of an imminent nuclear meltdown after the loss of cooling capabilities in the Fukushima-Daiichi power plant invoked widereaching global attention. The release of major amounts of radioactive material compelled the Japanese government to implement an exclusion zone within a 20-kilometer radius of the power plant, an area formerly populated by 80,000 people. The accident intensified the international discussion concerning the hazard of nuclear power plants as well as its effect on the countries' transition to alternative, clean energy forms. For instance, on March 14, only three days after the earthquake, the German government announced that it would thoroughly reconsider its nuclear energy policy and accelerate the changeover to alternative energies.

It is not surprising that the incident also affected in-
Figure 1: Nuclear and Clean Energy Indices

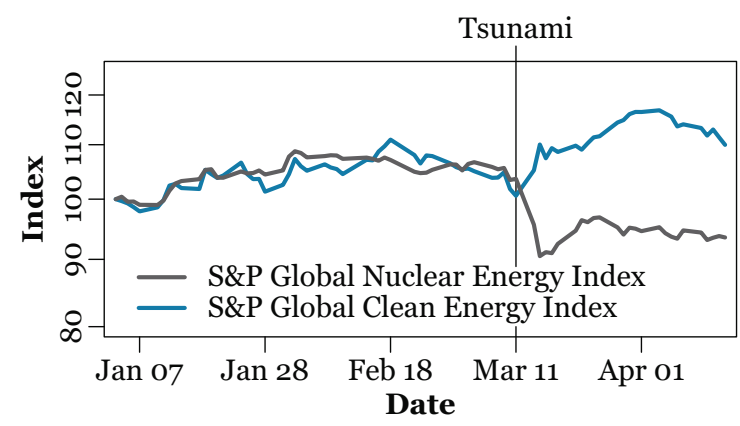

Relative index values of the S\&P Global Nuclear Energy Index and the S\&P Global Clean Energy Index normalized to an initial value of 100 on January 3, 2011.

Source: S\&P Index Data Platform.

ternational stock markets, particularly utility stock prices. For example, on the first and the second trading day after the disaster, i.e., March 14 and 15, daily returns of the S\&P Global Nuclear Energy Index, a worldwide index comprising 24 companies involved in nuclear businesses, were down by 
$-7.71 \%$ and $-5.35 \%$. On the contrary, daily returns of the S\&P Global Clean Energy Index were up by $4.55 \%$ and $4.63 \%$ on the same days. This index consists of 30 companies that are involved in clean energy-related businesses. Figure 1 shows the effect of the nuclear disaster in FukushimaDaiichi on both global indices. However, these indices pool stocks from very different markets, with the political convictions regarding nuclear power varying widely between nations. This study examines the impact of the Fukushima-Daiichi disaster separately on both a country and company level. Our data provide stock prices of nuclear power producers and alternative energy firms in France, Germany, Japan, and the United States. These countries formed the markets with the highest nuclear power output in 2009. Furthermore, we analyze the market efficiency throughout the period subsequent to the disaster.

There are several studies in finance literature, which focus upon the consequences of nuclear disasters such as the Three Mile Island (TMI) accident in March 1979 and the Chernobyl disaster in April 1986 on stock prices.

Bowen, Castanias, and Daley (1983) studied the effect of the TMI accident on daily returns of U.S. utility stocks. They found statistically significant, negative abnormal returns, in particular for firms with current or planned nuclear relations as well as a statistically significant long-run, upward shift in both residual risk and market risk after March 1979. Furthermore, firms with high nuclear commitments exhibit larger declines in equity prices than non-nuclear firms. Likewise, Hill and Schneeweis (1983) considered the effect of the TMI accident on the stock returns of U.S. public utility firms. They used monthly market data and found statistically significant, negative abnormal returns in the month of the TMI incident and the following month for nuclear utilities by applying single and two index models. The losses suffered by non-nuclear firms, however, are statistically not significant. Barrett, Heuson, and Kolb (1986) analyzed the effects of the TMI incident on bond risk premia in the public utility industry and revealed a statistically significant increase in the risk premia attached to all U.S. electric utility bonds subsequent to the TMI accident. In particular, firms with nuclear-generating capacity show a larger step-up in the risk premia following the TMI event than non-nuclear utility bonds.
Fields and Janjigian (1989) studied the U.S. public electric utility stock price reaction to the Chernobyl nuclear power plant disaster. During a 20-day period after the accident, they found statistically significant, negative daily abnormal returns for all firms. In particular, nuclear-related firms exhibited greater losses than non-nuclear firms. In contrast to Bowen, Castanias, and Daley (1983) who considered TMI, Fields and Janjigian (1989) did not find statistically significant changes in systematic risk, total risk, or market risk. Another study, which researched whether daily stock returns of U.S. electric utilities reacted to the Chernobyl nuclear catastrophe is the one by Kalra, Henderson jr., and Raines (1993), who grouped firms by their nuclear capacity. Although all groups delivered statistically significant, negative reactions on the Chernobyl accident, the mixed group with a nuclear capacity of $10 \%--20 \%$ performed worst. Aktar (2005) studied the impact of the nuclear accident in Chernobyl on equity prices of U.S. electric utilities and provided a comparison with the impact of TMI. He found a relatively greater impact on firms with a larger degree of nuclear exposure after the Chernobyl accident as well as for firms already experiencing problems with the Nuclear Regulatory Commission, in addition to firms with nuclear power plants under construction. Furthermore, he identified that negative stock price movements following TMI are greater for firms with plants located in densely populated areas. The same result does not apply to the Chernobyl accident.

Following this body of literature, we apply the event study methodology to investigate the impact of the nuclear disaster of Fukushima-Daiichi on daily stock returns in a five-week period following March 11, 2011. Our contribution to prior event studies on nuclear disasters is threefold.

Firstly, our data consist of a broader sample with respect to two dimensions: On the one hand, we examine the differences concerning the impact on stock prices between two distinct groups. While former studies are pooling all utility stocks, we separately consider two sub-samples, namely nuclear-related companies, on the one hand, and firms mainly involved in alternative energies on the other. Our analysis confirms the results from prior studies that a nuclear accident yields a decline of utility stock prices for the nuclear energy sub-sample. However, we also present strong evidence that alternative energy stocks benefit from 
a nuclear accident. On the other hand, we review hypotheses in an international context regarding four countries. Therewith, we extend the insights provided by prior studies, which contain results on the reaction of the stock prices in the United States only.

Secondly, while prior literature relied on a simple market model, our empirical approach implements a Fama-French model for stock returns. This allows us to draw conclusions that are independent of possible size effects in the sample of firms. Furthermore, instead of testing each firm individually for abnormal returns, we test our respective country-wise and sector-wise sub-samples for jointly significant abnormal returns.

Thirdly, to the best of our knowledge, we compose the first study to consider the effects of the Fukushima-Daiichi accident. While the nuclear accidents in TMI and Chernobyl induced significant reactions in U.S. utility stock prices, we find only weak evidence for similar reactions to the Fukushima-Daiichi accident in the United States. However, we present strong reactions in France, Germany, and Japan suggesting a possible forthcoming policy change in these countries.

Section 2 outlines the methodology regarding the stock return model and the hypotheses tests in this event study, whereas further technical details are given in Appendix A. We explain our research design and the sample selection in section 3. A detailed discussion of our results follows in section 4 .

\section{Methodology}

Primarily, we are interested in assessing the market efficiency following the Fukushima-Daiichi nuclear disaster. Pursuing the stream of literature founded by the seminal paper of Fama, Fisher, Jensen, and Roll (1969), we employ a traditional event study methodology to investigate the semistrong form of market efficiency in the sense that stock prices adjust very rapidly to information, which had newly been made publicly available. The analysis relies on the assumption that there have been no confounding effects besides the ones that will be considered separately (McWilliams and Siegel 1997). We use the following notation for the time windows of a stock return model and a completely unexpected event. Let $t_{0}$ be the beginning of the estimation period $\left[t_{0}, t_{1}-1\right], t_{1}$ be the event date, $t_{2}$ be the end of the event window $\left[t_{1}, t_{2}\right]$, and $t_{3}$ be the end of the post-event window $\left[t_{2}+1, t_{3}\right]$.

\subsection{Fama-French stock return model}

As MacKinlay (1997) pointed out, a multi-factor model should be considered in event studies when analyzing firms that are all members of the same industry. Therefore, in contrast to prior event studies on nuclear disasters that rely on the CAPM, we apply the Fama and French (1993) three-factor model. It incorporates two additional risk factors, which is relevant for our sample because the size of nuclear and alternative energy firms varies widely. For a single asset, let

(1) $R_{t}=\beta_{0}+\beta_{M} M_{t}+\beta_{S M B} S M B_{t}+$

$$
\beta_{H M L} H M L_{t}+\varepsilon_{t} \text {, }
$$

for $t=t_{0}, \ldots, t_{3}$, where $R_{t}$ is the return on a specific firm (throughout the paper, we denote the discrete return of an asset net of the risk-free rate simply as return), $M_{t}$ is the return on the market portfolio, $S M B_{t}$ is the return on the smallminus-big portfolio, $H M L_{t}$ is the return on the high-minus-low portfolio, and $\varepsilon_{t}$ represents the excess return on day $t$. For all $t$, equation (1) can be written in matrix form as

(2) $\boldsymbol{R}=\boldsymbol{X} \boldsymbol{\beta}+\boldsymbol{\varepsilon}$

where the design matrix

$$
\boldsymbol{X}=[\mathbf{1}|\boldsymbol{M}| \boldsymbol{S M B} \mid \boldsymbol{H M L}] \in \mathbb{R}^{\left(t_{3}-t_{0}+1\right) \times 4} .
$$

\subsection{Event study}

To include the effect of the event, we introduce dummy variables $\boldsymbol{D}_{t} \in \mathbb{R}^{t_{3}-t_{0}+1}, t=t_{1}, \ldots, t_{3}$, which are defined as indicator vectors with a one in row $t$ and zeros elsewhere. Notice that according to Acharya (1993), the dummy variable approach is equivalent to the standard two-step procedure employed in many event studies. Let $\boldsymbol{D}=\left[\boldsymbol{D}_{t_{1}}|\cdots| \boldsymbol{D}_{t_{3}}\right] \in \mathbb{R}^{\left(t_{3}-t_{0}+1\right) \times\left(t_{3}-t_{1}+1\right)}$. Therewith we extend equation (2) to

（3） $\boldsymbol{R}=\boldsymbol{X} \boldsymbol{\beta}+\boldsymbol{D} \boldsymbol{\gamma}+\boldsymbol{\varepsilon}$,

where $\boldsymbol{\gamma} \in \mathbb{R}^{t_{3}-t_{1}+1}$ indicates the abnormal returns in the event window and in the post-event window. For a set of multiple assets, define analogously to equation (3) the multivariate regression model (MVRM)

(4)

$\boldsymbol{R}_{i}=\boldsymbol{X} \boldsymbol{\beta}_{i}+\boldsymbol{D} \boldsymbol{\gamma}_{i}+\boldsymbol{\varepsilon}_{i}, \quad i=1, \ldots, g$, 
where $g$ denotes the total number of firms. These firms comprise nuclear companies, denoted in the index set $N$, and alternative energy companies, denoted in the index set $A$, such that $\{1, \ldots, g\}=$ $N \cup A$.

\subsection{Hypothesis development}

Given the fact that abnormal returns were documented for nuclear and non-nuclear utility firms during the first two major nuclear accidents in TMI (Bowen, Castanias, and Daley 1983; Hill and Schneeweis 1983) and Chernobyl (Fields and Janjigian 1989; Kalra, Henderson jr., and Raines 1993), we establish similar hypotheses for the Fukushima-Daiichi disaster. Normally, a nuclear accident raises the general awareness of the possible risks of nuclear energy. Supervisory authorities overhaul existing safety procedures, which may lead to costly retrofits in nuclear power plants. Thus, we expect a decline in the stock prices of nuclear energy firms after a nuclear disaster. Moreover, policymakers might launch programs to expedite the transition to non-nuclear, alternative energies. Such programs should increase the demand for alternative energies. Therefore, we expect the stock prices of alternative energy firms to rise in expectation of such programs. This yields the following testable hypotheses.

$H_{1}$ : The event does not affect the abnormal returns of the nuclear energy stocks in the (post-)event window.

$\mathrm{H}_{2}$ : The event does not affect the abnormal returns of the alternative energy stocks in the (post-) event window.

$H_{3}$ : The event does not affect the cumulative abnormal returns of the nuclear energy stocks in the (post-)event window.

$H_{4}$ : The event does not affect the cumulative abnormal returns of the alternative energy stocks in the (post-)event window.

We test these hypotheses individually for each country on each day in the event window and the post-event window. Significant abnormal and cumulative abnormal returns during the event window would suggest that the market expects a change in policy towards non-nuclear energies. Moreover, finding significant abnormal returns in the event window, while finding no significant abnormal returns in the post-event window would indicate a rapid adjustment of the stocks' prices to the new regime and thus support the concept of market efficiency. Technical details on the tests are provided in Appendix A.

\section{Research design}

\subsection{Choice of window lengths and three-factor model estimation}

Although many event studies use a relatively short estimation period to avoid incorporating confounding events, we follow the event studies on nuclear disasters of Bowen, Castanias, and Daley (1983); Hill and Schneeweis (1983) which use an estimation period of three and two years, respectively. Hence, we estimate the model for a period of three years commencing on January 4, 2008 and ending on March 10, 2011. Moreover, given the extreme bull market after the financial crisis of 2007-2009, we consider betas based on a shorter estimation period to be non-stationary. We consider two event windows when testing for short-run and medium-run market reactions in the abnormal returns of selected energy companies. The event window commences on March 14, 2011 (i.e., the first trading day after the disaster) and spans a period of five trading days. Further, we define a post-event window from March 21, 2011 to April 15, 2011.

We use Thomson Reuters Datastream as our primary data source. To be precise, we use the datatype Price Adjusted (P) as the stock price, Market Value (MV) as the market value, and Common/Shareholder Equity (WC03501) as the book value. In order to compute the returns of the Fama-French portfolios, we consider all domestic equities with the aforementioned datatypes available that are listed on the NYSE Euronext for France (295 stocks), Börse Frankfurt for Germany (230 stocks), Tokyo Stock Exchange for Japan (2,264 stocks), and NYSE, AMEX, and NASDAQ for the United States (3,876 stocks), respectively. The selected stocks account for a total market capitalization of $€ 1.242$ trillion (France), $€ 907$ billion (Germany), ¥309.522 trillion (Japan), and \$14.022 trillion (USA), respectively, as of December 31, 2010. For each of the four markets, we compute the market portfolio returns, 
the small-minus-big (SMB) portfolio returns and the high-minus-low (HML) portfolio returns. Similar to Fama and French (1993), we rebalance the SMB and HML portfolio on June 30 each year. In order to consistently define the portfolios in all markets, we use the median of the market capitalization of all stocks in the respective market as of June 30 as the threshold for the SMB portfolio, and the $30 \%$ and $70 \%$ quantile of the stocks ordered by the book-to-market equity as of December 31 of the previous year as the thresholds for the HML portfolio. When comparing the factors of our U.S. sub-sample to the factors published on Kenneth French's website (http://mba.tuck.dartmouth.edu/pages/ faculty/ken.french/data_library.html), we obtain a correlation of $99.9 \%$ for the market portfolio returns, $91.0 \%$ for the SMB portfolio returns, and $79.5 \%$ for the HML portfolio returns. Although the correlations for the SMB and HML portfolios are still high, the decrease compared to the correlation of the market portfolio can be explained: Kenneth French uses the median market capitalization of the NYSE stocks only as the threshold for the SMB portfolio, while we use the median of all U.S. stocks. As a proxy for the risk-free rates, we take the one-month EURIBOR for France and Germany, the one-month Gensaki T-Bill rate for Japan, and the four-week U.S. T-Bill rate for the United States.

\subsection{Nuclear and alternative companies sample selection}

We consciously choose our sample in respect to several criteria that ensure a robust estimation of the stock return model. Moreover, we do not consider supplying industries to guarantee a very low international linkage of the four different country samples.

Because there is no category for nuclear companies in Datastream, we select all publicly traded companies operating nuclear power plants with a capacity of at least 1,000 megawatts that are domestic to their respective market. However, we exclude EnBW for Germany which had only approximately $1 \%$ of its stocks in free float in March 2011. Table B-1 in Appendix B lists the companies and their respective nuclear power capacity.

For the alternative energy firms, we use all stocks in Thomson Reuters Datastream, which are classified as Alternative Energy. However, we filter out all illiquid stocks with more than 90 days of no trading reported in the estimation period, or five days without trading reported in the event windows. This affects 3 firms (France), 10 firms (Germany), o firms (Japan), and 43 firms (USA). Afterwards, there remain: 1 stock (France), 13 stocks (Germany), 1 stock (Japan), and 13 stocks (USA). Finally, we filter out all stocks for which the Fama-French model fits with a coefficient of determination of less than 0.15 . The rationale behind this is that a small $R^{2}$ value indicates an inferior fit of the Fama-French model. Notice that the event study methodology compares the actual returns with the predicted returns by the Fama-French model. Therefore, no meaningful forecast of the return is possible for stocks exhibiting a poor fit of the Fama-French model. This is the case for five stocks in Germany and six stocks in the United States. The remaining stocks are listed in Table B-1 in Appendix B.

\subsection{Confounding events}

Foster (1980) suggested several approaches to prevent an impact of confounding events occurring in the event window. Following him, we eliminate a firm from the sample on the days of confounding events. Technically, we ignore the respective abnormal returns on these days (i.e., to gain an unbiased estimate of the cumulative abnormal return for the individual companies) and exclude the company on the respective days when calculating mean ARs and CARs. Table B-2 contains a list of all confounding events affecting the firms of the sample in the period from March 11 to April 15, 2011.

\section{Results and discussion}

The three key results of our empirical study of the Fukushima-Daiichi nuclear disaster are: (1) the unanticipated event is incorporated in the stock prices of selected nuclear and alternative energy companies within a few days, thus supporting the concept of semi-strong market efficiency, (2) nuclear energy companies have significant negative cumulative abnormal returns while alternative energy companies show a positive reaction, and (3) the majority of abnormal returns in the postevent window are caused by confounding events. 


\subsection{Fama-French model}

We estimate the full multivariate regression model in equation (A.1) separately for each country using its specific Fama-French portfolios, as described in the previous section. Table 1 presents descriptive statistics upon the asset pricing model fit during the estimation period from January 4, 2008 to March 10, 2011. Our selected alternative energy companies are generally riskier than the nuclear companies in all countries. The nuclear energy companies have a market beta lower than one, and a negative, but relatively low exposure to the small-minus-big (SMB) factor. However, the alternative energy companies display a high positive exposure to the SMB factor. These companies have a much smaller market capitalization than the nuclear companies and are therefore subject to the size effect (i.e., smaller stocks have higher average returns). Comparing the exposure to the highminus-low (HML) factor, we find that the nuclear stocks have lower factor loadings than the alternative energy stocks in all markets except Japan. This is commensurate with the explanation of Fama and French (1995), being that stronger firms generally exhibit lower HML factors. Moreover, the model generally fits the nuclear stocks better than the alternative energy stocks.

Figure 2 exhibits the estimated residual correlations of all firms in each country. The nuclear energy firms exhibit an average correlation of 0.62 (Germany), 0.72 (Japan), and 0.44 (USA). For the alternative energy firms, the average correlations are 0.18 (Germany) and 0.14 (USA). The average correlations between the nuclear and alternative energy firms are 0.04 (France), 0.03 (Germany), -0.01 (Japan), and -0.03 (USA). The joint hypothesis tests in the following section account for these correlations within both sectors.

\subsection{Abnormal returns}

On March 14, the first trading day after the danger in Fukushima-Daiichi became imminent, the nuclear energy firms in France, Germany, and Japan show significant negative abnormal returns (Table 2), whereas we do not find significant abnormal returns for the nuclear companies in the United States. Notice that we present the mean of the abnormal returns (AR) and cumulative abnormal returns (CAR) in this table. Since performance distributions often tend to be skewed, we addition- ally provide the results for the median $\mathrm{AR}$ and CAR in the Appendix (Table B-6). Yet, the significance levels are not based on testing the hypothesis of zero mean (cumulative) abnormal returns, but on jointly zero (cumulative) abnormal returns (joint hypothesis tests in section 2.3 and Appendix A). We provide detailed results on a company level for each country in Appendix B (Tables B-3-B-5). The mean cumulative abnormal returns of the nuclear energy firms in all countries remain negative during the event window. However, the CAR of the U.S. nuclear stocks is not significant at the end of the event window (March 18, 2011), and the French and German CARs on nuclear stocks are merely slightly significant at a $10 \%$ level. Only the Japanese nuclear stocks show jointly significant non-zero CARs at a $1 \%$ level with a mean of $-9.9 \%$. As expected, we see an inverted effect for the alternative energy companies. They profit in all countries except the United States in the event window. When grouping the alternative companies into their subsegments (cf. Table B-1), the CARs at the end of the event window are the highest for the solar energy producers in France (13.4\%) and in Germany (52.6\%). To sum up, in our sample we find an expected short-term negative reaction for the majority of the nuclear stocks and note a positive performance for the alternative companies.

To study medium-term effects of the events on the abnormal returns we consider a post-event window of four weeks commencing on March 21, 2011. The significant abnormal returns in France for EDF on April 5 and $6(-3.1 \%$ and $-2.7 \%)$ were most likely due to an announcement of the French government concerning their low energy price strategy. Otherwise, we did not notice medium-term effects on the nuclear and the alternative company in the French sample. The CARs of the German nuclear producers are not jointly significantly non-zero in the post-event window (Table 2). However, we find many highly significant abnormal returns for the eight German alternative companies in our sample (Table B-3). Nevertheless, most of these can be explained. In particular, the German solar producers had high CARs during the event window. Therefore, we conclude that the significant negative abnormal returns at the beginning of the post-event window are mostly due to profit-taking. Later, we found several confounding events (Table B-2). For example, on March 27 the Green Party won the election in the German federal state of Baden- 
Table 1: Fama-French three-factor model

Panel (a): Nuclear Stocks

\begin{tabular}{lcrrrr} 
& France & Germany & \multicolumn{1}{c}{ Japan } & \multicolumn{1}{c}{ USA } \\
\hline$\beta_{M}$ & $0.91(0.00)$ & $0.81(0.13)$ & $0.40(0.04)$ & $0.72(0.15)$ \\
\hline$\beta_{S M B}$ & $-0.01(0.00)$ & $-0.14(0.05)$ & $-0.07(0.05)$ & $-0.34(0.14)$ \\
\hline$\beta_{H M L}$ & $-1.00(0.00)$ & $-1.01(0.17)$ & $0.69(0.10)$ & $-0.42(0.17)$ \\
\hline$R^{2}$ & $0.54(0.00)$ & $0.59(0.03)$ & $0.43(0.16)$ & $0.49(0.09)$
\end{tabular}

Panel (b): Alternative Energy Stocks

\begin{tabular}{lcrcr}
\cline { 2 - 5 } Factor & France & Germany & Japan & \multicolumn{1}{c}{ USA } \\
\hline$\beta_{M}$ & $1.13(0.00)$ & $1.87(0.51)$ & $1.17(0.00)$ & $1.49(0.38)$ \\
\hline$\beta_{S M B}$ & $1.14(0.00)$ & $0.99(0.54)$ & $1.18(0.00)$ & $0.74(0.39)$ \\
\hline$\beta_{H M L}$ & $-0.00(0.00)$ & $-0.84(0.29)$ & $0.50(0.00)$ & $-0.13(0.53)$ \\
\hline$R^{2}$ & $0.15(0.00)$ & $0.28(0.10)$ & $0.39(0.00)$ & $0.26(0.09)$
\end{tabular}

We display the mean Fama-French factors for nuclear and alternative energy firms in the respective markets and their standard deviation (in parentheses). We also list the mean and standard deviation (in parentheses) of the (non-adjusted) $R^{2}$ values of the three-factor model in the different markets. The estimation period commences on January 4, 2008 and ends on March 10, 2011.

\section{Figure 2: Correlation matrices}

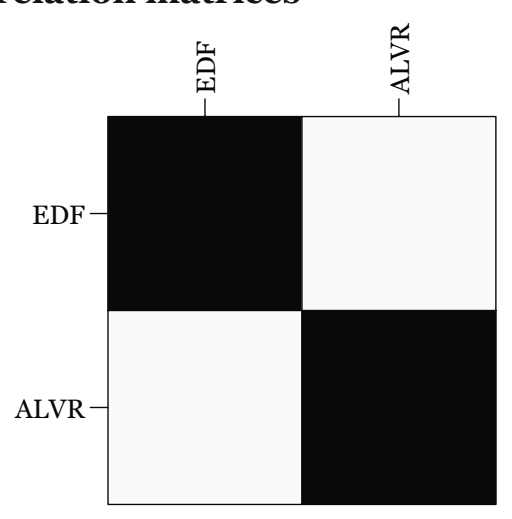

(a) France

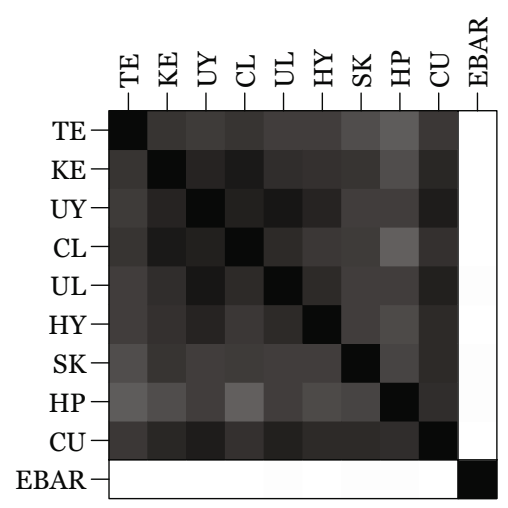

(c) Japan

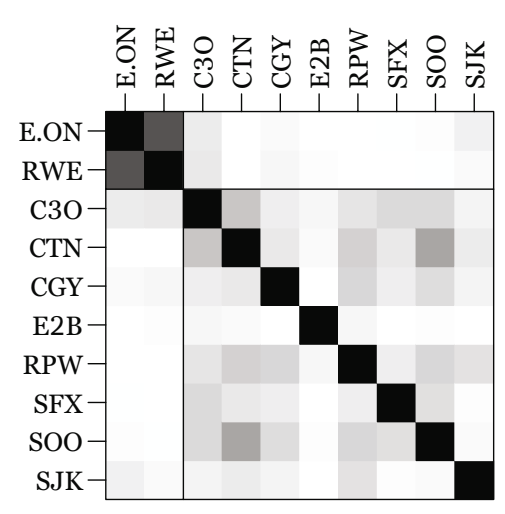

(b) Germany

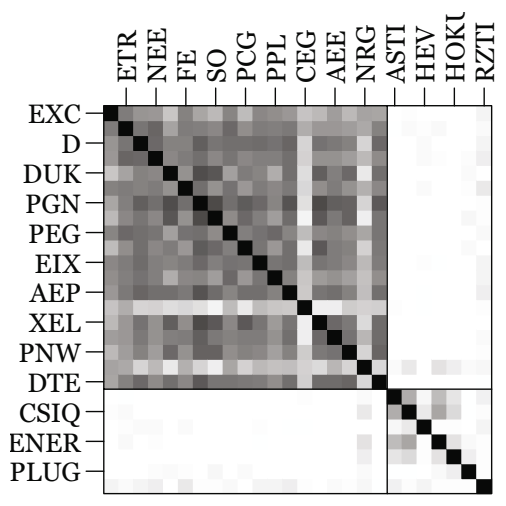

(d) USA

Correlation matrices of all nuclear and alternative energy stock residual returns in each country estimated by the MVRM for the period January 4, 2008 through March 10, 2011. White represents negative and zero correlations, black represents a correlation of one. Nuclear stocks are plotted in the upper-left corner and alternative energy stocks in the lower-right corner. The nuclear and alternative energy stocks are separated by black lines. The numeric correlation matrices can be downloaded as an online supplementary material. 
Table 2: Mean daily ARs and mean daily CARs of nuclear and alternative energy companies

Nuclear Stocks

Alternative Energy Stocks

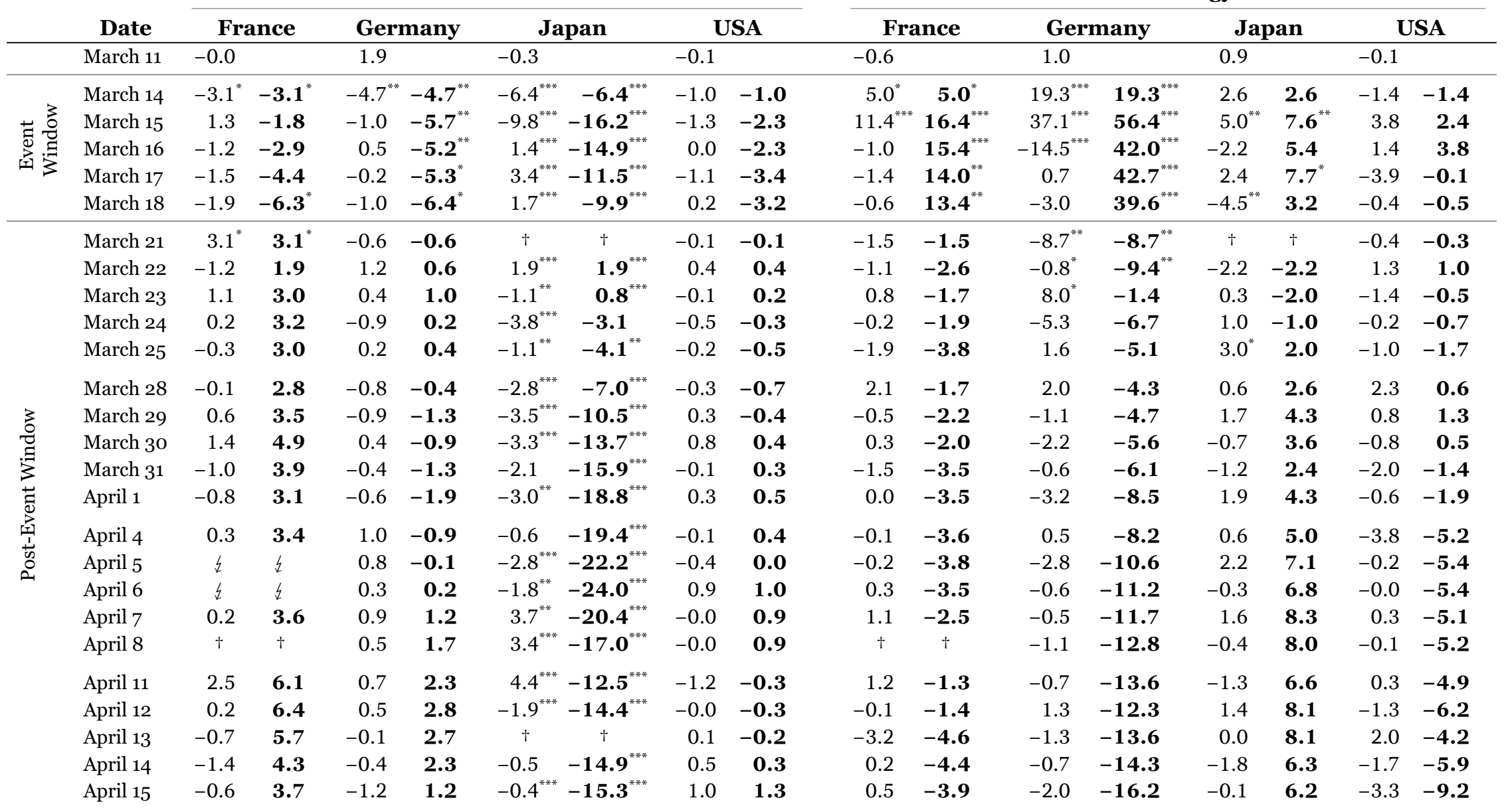

Mean daily abnormal returns (in regular letters) and mean daily cumulative abnormal returns (in bold letters) of nuclear and alternative energy companies in the respective

markets. All values are given in percentage. ${ }^{*},{ }^{* *},{ }^{* * *}$ denote joint significant (cumulative) abnormal returns at a $10 \%$, $5 \%$, and $1 \%$ level, respectively, corresponding to the hypotheses given in section 2.3. The p-values (not reported separately) are calculated using a MVRM and the HWZ bootstrap method as described in Hein and Westfall (2004) with 100,000

bootstrap samples each. Confounding events according to Table B-2 are excluded from the analysis and marked with \&, holidays are marked with $\dagger$. 
Württemberg, which had a significant positive effect on the solar energy companies. The CARs for the Japanese nuclear companies are jointly significantly different from zero at a $1 \%$ level with a mean of $-15.3 \%$ at the end of the post-event window (Table 2). Of course the mean is influenced by the abnormal returns of TEPCO, with the median being $-10.1 \%$ (Table B-6). However, we find several significant negative abnormal returns for the other nuclear stocks (Table B-4). We identified only one confounding event in the post-event window for Japan. On April 13, 2011 there was news that TEPCO's liability would be capped while other utilities could have been asked to cover on some of the compensation costs. As a result, we find significant negative returns for all Japanese nuclear stocks except for TEPCO on this particular day (Table B-4). For the United States, the post-event window consists of only two significant abnormal returns for the nuclear companies, both being due to confounding events. Furthermore, seven significant negative abnormal returns for the alternative energy companies exist, amongst which five were caused by confounding events. Therefore, we do not see medium-term effects for the U.S. companies in our sample in the post-event window. In summary, one can conclude that the majority of abnormal returns in the post-event window are explained by confounding events. Jointly significantly non-zero CARs remain in the post-event window only for the Japanese nuclear producers. Longer-lasting effects upon energy companies in France, Germany and the United States cannot be inferred from the analyzed market data.

Comparing the mean CARs at the end of the event window and the post-event window, we find that the strong reactions of the returns one week after the event are partially offset after five weeks in France, Germany, and the United States. This would indicate an overreaction in the stock prices during the first few days following the Fukushima-Daiichi disaster. However, notice that the vast majority of the ARs and CARs of the reversal in the post-event window are not significant. In contrast, most of the significant abnormal returns occur within the first two trading days after the event. Therefore, the rapid adjustment of the stock prices supports the efficient market hypothesis in its semi-strong form in all countries except Japan. This is plausible because the Japanese companies are influenced by aftershocks following the initial earthquake, and by the discussion about the distribution of the compensation costs to other utilities and the Japanese government.

\subsection{Robustness checks}

To gauge the robustness of our results we examined several alternative specifications of the model. In a first check we reduced the size of the estimation period and set $t_{0}=$ January 4 , 2009. This did not materially affect the estimates of the coefficients of interest and we again found similar results for the significance of the (cumulative) abnormal returns. Furthermore, we re-analyzed the Japanese nuclear sample excluding TEPCO as the directly affected company in Fukushima-Daiichi. In this case, the mean CARs remain negative in Japan on all days with $-3.0 \%$ at the end of the event window and $-8.9 \%$ at the end of the post-event window. However, only the CARs at the end of the event window remain jointly significantly non-zero at a $1 \%$ level, whereas the joint significance of the CARs at the end of the post-event window diminishes. Moreover, we re-evaluated our study using logarithmic returns instead of discrete returns. While the interpretation of the mean logarithmic CARs is difficult (Dissanaike and Le Fur 2003), we did not detect any material differences in the results. Finally, we wish to point out that the bootstrap procedure in section 2.3 and Appendix A already accounts for the non-normality and possible heteroscedasticity due to GARCH effects of the residuals and thus leads to robust significance levels in the joint hypotheses tests.

\section{Conclusion}

This study provides profound insights into the effects of the Fukushima-Daiichi disaster on selected nuclear and alternative energy stocks in four different countries. For the Japanese nuclear stocks, we note a distinct increase in volatility following the event, which implies a high amount of uncertainty about future policy implications. In contrast, the French and German stock prices adjusted rapidly after the event, indicating that the market expects a change in policy towards alternative energies. Finally, our findings suggest that the market does not expect a forthcoming policy departure in the United States. 


\section{Appendix A: Model estimation and joint hypothesis tests}

The standard approach employed in many event studies is merely to examine the mean of the abnormal returns of all assets under consideration (e.g., Harrington and Shrider 2007), i.e., to consider the mean of equation (4) for $i=1, \ldots, g$. However, we cannot assume a priori that all nuclear and alternative energy firms are affected in the same way because the portion of nuclear power in the firm's generation mix varies widely between the nuclear energy firms. Furthermore, the alternative energy firms are engaged in different subsegments. Therefore, we proceed with the estimation of the complete stacked MVRM

$$
\left[\begin{array}{c}
\boldsymbol{R}_{1} \\
\boldsymbol{R}_{2} \\
\vdots \\
\boldsymbol{R}_{g}
\end{array}\right]=\underbrace{\left[\begin{array}{cccccc}
\boldsymbol{X} \boldsymbol{D} & 0 & 0 & \cdots & 0 & 0 \\
0 & 0 & \boldsymbol{X} \boldsymbol{D} & \cdots & 0 & 0 \\
\vdots & \vdots & \ddots & \vdots \\
0 & 0 & 0 & 0 & \cdots & \boldsymbol{X} \boldsymbol{D}
\end{array}\right]}_{=: \Xi} \underbrace{\left[\begin{array}{c}
\boldsymbol{\beta}_{1} \\
\boldsymbol{\gamma}_{1} \\
\vdots \\
\boldsymbol{\beta}_{g} \\
\boldsymbol{\gamma}_{g}
\end{array}\right]}_{=: \boldsymbol{\delta}}+\left[\begin{array}{c}
\boldsymbol{\varepsilon}_{1} \\
\boldsymbol{\varepsilon}_{2} \\
\vdots \\
\boldsymbol{\varepsilon}_{g}
\end{array}\right] .
$$

According to Binder (1998), the benefit of this framework is twofold: Firstly, it empowers the testing of more sophisticated joint hypotheses than just the average return on all assets. Secondly, it allows one to directly employ cross-sectional correlations in the test statistics, which is of particular importance in our case, where all firms share the same industry and the same event window.

Since the stacked MVRM in equation (A.1) is a special case in the class of seemingly unrelated regressions (SUR), traditional parametrical methodologies for testing joint hypotheses in SUR models can be directly applied and are discussed, e.g., in Binder (1985). All these methods rely on the assumption that the first $t_{1}-1$ rows (i.e., the rows corresponding to the estimation period) of the residuals $\boldsymbol{\varepsilon}=\left[\boldsymbol{\varepsilon}_{1}|\cdots| \boldsymbol{\varepsilon}_{g}\right]$ are independent and identically distributed, whereas the observations within each row may be cross-sectionally correlated. However, Hein and Westfall (2004) pointed out that these tests are not robust to non-normality of the residuals, even for an arbitrarily large estimation period, and propose using bootstrap methods instead. They showed that bootstrapping adapts itself to non-normal characteristics of the data, and is even marginally robust to non-i.i.d. data. In an empirical study, Hein and Westfall (2004) demonstrated that bootstrapping procedures are capable of capturing $\mathrm{AR}, \mathrm{ARCH}$, and GARCH effect very well. Hence, we follow suit and use the HWZ bootstrap method as described in Hein and Westfall (2004) for calculating $p$-values. In particular, this method is a data-based bootstrap of the test statistic

$$
S=(\boldsymbol{A} \hat{\boldsymbol{\delta}})^{\prime}\left(\boldsymbol{A}\left(\boldsymbol{\Xi}^{\prime}\left(\hat{\boldsymbol{\Sigma}} \otimes \boldsymbol{I}_{t_{2}-t_{0}+1}\right)^{-1} \boldsymbol{\Xi}\right)^{-1} \boldsymbol{A}^{\prime}\right)^{-1}(\boldsymbol{A} \hat{\boldsymbol{\delta}}),
$$

where $\boldsymbol{A}$ is a linear hypotheses test matrix, $\boldsymbol{\Xi}$ the design matrix from equation (A.1), $\hat{\boldsymbol{\delta}}$ the estimation of the $\boldsymbol{\beta}$ and $\boldsymbol{\gamma}$ vector from equation (A.1), $\boldsymbol{I}$ the identity matrix, $\otimes$ the Kronecker product, and $\hat{\boldsymbol{\Sigma}}$ the estimated covariance matrix of the residuals $\boldsymbol{\varepsilon}_{i}, i=1, \ldots, g$, from equation (A.1). Notice that the test statistic $S$ is already adjusted for cross-sectional correlations of the securities by incorporating the estimated covariance matrix $\hat{\boldsymbol{\Sigma}}$. Therefore, we do not require any crude dependence adjustments of the (cumulative) abnormal returns.

Finally, we describe the hypothesis test matrices $\boldsymbol{A}_{1}, \ldots, \boldsymbol{A}_{4}$ corresponding to the four hypotheses $H_{1}, \ldots, H_{4}$. Formally, for a day $\tau \in\left[t_{1}, t_{2}\right]$, we can re-write the hypotheses from section 2.3 as

$H_{1}:\left(\boldsymbol{\gamma}_{i}\right)_{\tau}=0$ for all $i \in N$,

$H_{2}:\left(\boldsymbol{\gamma}_{i}\right)_{\tau}=0$ for all $i \in A$,

$H_{3}: \sum_{t=t_{1}}^{\tau}\left(\boldsymbol{\gamma}_{i}\right)_{\tau}=0$ for all $i \in N$,

$H_{4}: \sum_{t=t_{1}}^{\tau}\left(\boldsymbol{\gamma}_{i}\right)_{\tau}=0$ for all $i \in A$,

and similar for $\tau \in\left[t_{2}+1, t_{3}\right]$. Technically speaking, we now define the test matrix $\boldsymbol{A}_{1}(\tau)$ corresponding to hypothesis $H_{1}$ for a day $\tau \in\left[t_{1}, t_{3}\right]$ as a $|N| \times|\boldsymbol{\delta}|$ matrix, where $|\boldsymbol{\delta}|$ denotes the size of the vector $\boldsymbol{\delta}$ and $|N|$ the number of nuclear energy firms, with a one in every row $n \in N$ at column $(n-1)\left(t_{3}-t_{1}+5\right)+\tau-t_{1}+4$ and zeros elsewhere. The hypothesis test matrix $\boldsymbol{A}_{2}(\tau)$ corresponding to hypothesis $\mathrm{H}_{2}$ is constructed similarly. Finally, the hypotheses test matrices for the cumulative hypotheses $H_{3}$ and $H_{4}$ are constructed as $\boldsymbol{A}_{3}(\tau)=\sum_{t=t_{1}}^{\tau} \boldsymbol{A}_{1}(t)$ and $\boldsymbol{A}_{4}(\tau)=\sum_{t=t_{1}}^{\tau} \boldsymbol{A}_{2}(t)$ when testing cumulative abnormal returns in the event window, and $\boldsymbol{A}_{3}(\tau)=\sum_{t=t_{2}+1}^{\tau} \boldsymbol{A}_{1}(t)$ and $\boldsymbol{A}_{4}(\tau)=\sum_{t=t_{2}+1}^{\tau} \boldsymbol{A}_{2}(t)$ when testing in the postevent window. 


\section{Appendix B: Tables}

This Appendix contains tables which present the companies selected in this study (Table B-1), the confounding events considered (Table B-2), and the detailed daily abnormal returns for Germany, Japan, and the United States (Tables B-3-B-5).

\section{Table B-1: Nuclear holding companies and alternative energy companies}

France

\begin{tabular}{lll}
\hline EDF & Électricité de France & 63,130 \\
\hline$A L V R$ & Vergnet $S . A$. Act. au Port. & $S, H, W$
\end{tabular}

\section{Germany}

\begin{tabular}{llr}
\hline EON & E.ON & 11,329 \\
\hline RWE & RWE & 6,295 \\
\hline$C_{3} O$ & Centrosolar Group & $S$ \\
\hline$C T N$ & Centrotherm Photovoltaics & $S$ \\
\hline$C G Y$ & Conergy & $S$ \\
\hline$E 2 B$ & EOP Biodiesel & $B$ \\
\hline$R P W$ & Repower Systems & $W$ \\
\hline$S F X$ & Solar Fabrik & $S$ \\
\hline$S O O$ & Solon & $S$ \\
\hline$S J K$ & Systaic & $S$
\end{tabular}

\section{Japan}

\begin{tabular}{llr}
\hline TE & Tokyo Elec. Power Co. & 16,779 \\
\hline KE & Kansai Elec. Power Co. & 9,284 \\
\hline UY & Kyushu Elec. Power Co. & 5,004 \\
\hline CL & Chubu Elec. Power Co. & 3,360 \\
\hline UL & Tohoku Elec. Power Co. & 3,157 \\
\hline HY & Hokkaido Elec. Power Co. & 1,966 \\
\hline SK & Shikoku Elec. Power Co. & 1,922 \\
\hline HP & Hokuriku Elec. Power Co. & 1,613 \\
\hline CU & Chugoku Elec. Power Co. & 1,228 \\
\hline EBAR & Ebara Jitsugyo Co. & $H, W$
\end{tabular}

USA

\begin{tabular}{|c|c|c|}
\hline EXC & Exelon Corp. & 16,715 \\
\hline ETR & Entergy Corp. & 10,129 \\
\hline $\mathrm{D}$ & Dominion Resources & 5,691 \\
\hline $\mathrm{FE}$ & FirstEnergy Corp. & 3,862 \\
\hline PGN & Progress Energy & 3,771 \\
\hline $\mathrm{SO}$ & Southern Co. & 3,644 \\
\hline PEG & Public Service Ent. Grp. & 3,611 \\
\hline PCG & PG\&E Corp. & 2,240 \\
\hline EIX & Edison International & 2,236 \\
\hline PPL & PPL Corp. & 2,093 \\
\hline $\mathrm{AEP}$ & American Elec. Power Co. & 2,069 \\
\hline CEG & Constellation Energy Grp. & 1,939 \\
\hline XEL & Xcel Energy & 1,668 \\
\hline $\mathrm{AEE}$ & Ameren Corp. & 1,190 \\
\hline PNW & Pinnacle West Capital Corp. & 1,147 \\
\hline NRG & NRG Energy & 1,126 \\
\hline DTE & DTE Energy Co. & 1,122 \\
\hline$A S T I$ & Ascent Solar Technologies & $S$ \\
\hline CSIQ & Canadian Solar & $S$ \\
\hline$H E V$ & Ener1 & $F$ \\
\hline ENER & Energy Conversion Devices & $S, F$ \\
\hline $\mathrm{HOKU}$ & Hoku & $S$ \\
\hline$P L U G$ & Plug Power & $F$ \\
\hline$R Z T I$ & Raser Technologies & $G$ \\
\hline
\end{tabular}

Nuclear holding companies (in upright letters) with a capacity greater than 1,ooo megawatts (MW) and alternative energy companies (in italic letters) by country. The figures indicate the nuclear capacity (in megawatts). The alternative energy firms are classified into solar energy $(S)$, hydropower $(H)$, wind energy $(W)$, fuel cell technology $(F)$, geothermal electric power plants $(G)$ and biodiesel $(B)$.

Sources: Annual reports of EDF, E.ON, and RWE (2010) for France and Germany; International Atomic Energy Agency (2010) for Japan; Nuclear Energy Institute (2011) for USA; Thomson Reuters Datastream for alternative energy firms. 
Table B-2: Confounding events during the event and post-event window.

Date

March 11

March 28-March 30
Company

\section{Confounding Event}

ENER Company announcement regarding bad revenue guidance in the second half of 2011 on March 11.

CTN, CGY, Green Party wins the election in the German federal state of BadenSFX, SOO, Württemberg on March 27.

SJK

\begin{tabular}{lll}
\hline March 29 & PLUG & Inter RAO UES acquires 82 percent of Plug Power. \\
\hline March 31-April 4 & E2B & Takeover of EOP Biodiesel on March 31, 2011. \\
\hline April 1-April 4 & ASTI & $\begin{array}{l}\text { Company announcement regarding a change in corporate strategy. } \\
\text { Subsequently, the CEO resigns from his position. }\end{array}$ \\
\hline April 1-April 5 & SJK & $\begin{array}{l}\text { Insolvency proceedings; all outstanding accounts have to be settled by } \\
\text { March 29, 2011. }\end{array}$
\end{tabular}

\begin{tabular}{lll}
\hline April 4 & RPW & Takeover intention by the Indian company Suzlon. \\
\hline April 5-April 6 & EDF & Announcement by the French government concerning their low energy
\end{tabular}
price strategy.

\begin{tabular}{lll}
\hline April 5-April 7 & RZTI & $\begin{array}{l}\text { Default on the annual interest payment of } \$ 2.2 \text { million on April 1, 2011. } \\
\text { RYTI cannot provide any assurance that the payment will be made at all. }\end{array}$ \\
\hline April 12 & PPL & $\begin{array}{l}\text { PPL Corp. announces that it has priced its concurrent offerings of } \\
\text { common stock and equity units at a reference price of } \$ 25.30 \text { per share. }\end{array}$ \\
\hline April 12 & EIX & $\begin{array}{l}\text { Request for } \$ 64 \text { million for a study to re-evaluate the seismic and } \\
\text { tsunami conditions of its San Onofre Nuclear Generating Station. }\end{array}$ \\
\hline April 13 & $\begin{array}{l}\text { TE, KE, UY, } \\
\text { CL, UL, HY, } \\
\text { SK, HP, CU }\end{array}$ & $\begin{array}{l}\text { Besides TEPCO, several other nuclear energy firms have to render } \\
\text { side-payments totaling approximately } \$ 50 \text { billion. }\end{array}$ \\
\hline
\end{tabular}


Table B-3: Daily abnormal returns of nuclear and alternative energy companies in Germany

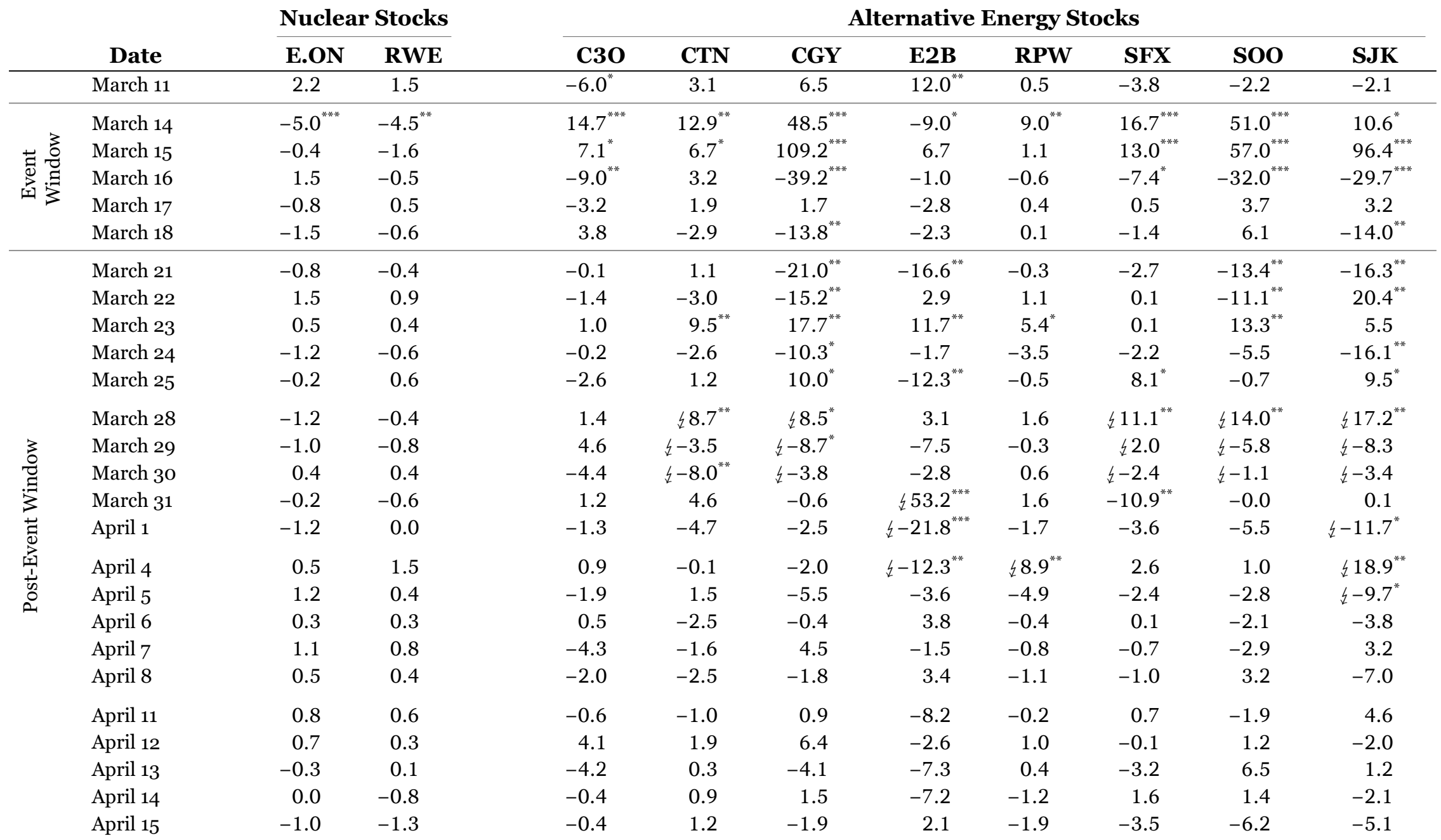

All values are given in percent. The nuclear companies are listed in descending order by their megawatt capacities. ****,**** denote significant abnormal returns at a $10 \%, 5 \%$, and $1 \%$ level, respectively. The p-values (not reported separately) are calculated using a MVRM and the HWZ bootstrap method as described in Hein and Westfall (2004) with 100,000 bootstrap samples each. Returns on days exhibiting possible confounding events according to Table B-2 are marked with \&, holidays are marked with $\dagger$. 
Table B-4: Daily abnormal returns of nuclear and alternative energy companies in Japan

\section{Nuclear Stocks}

Alt. Energy Stocks

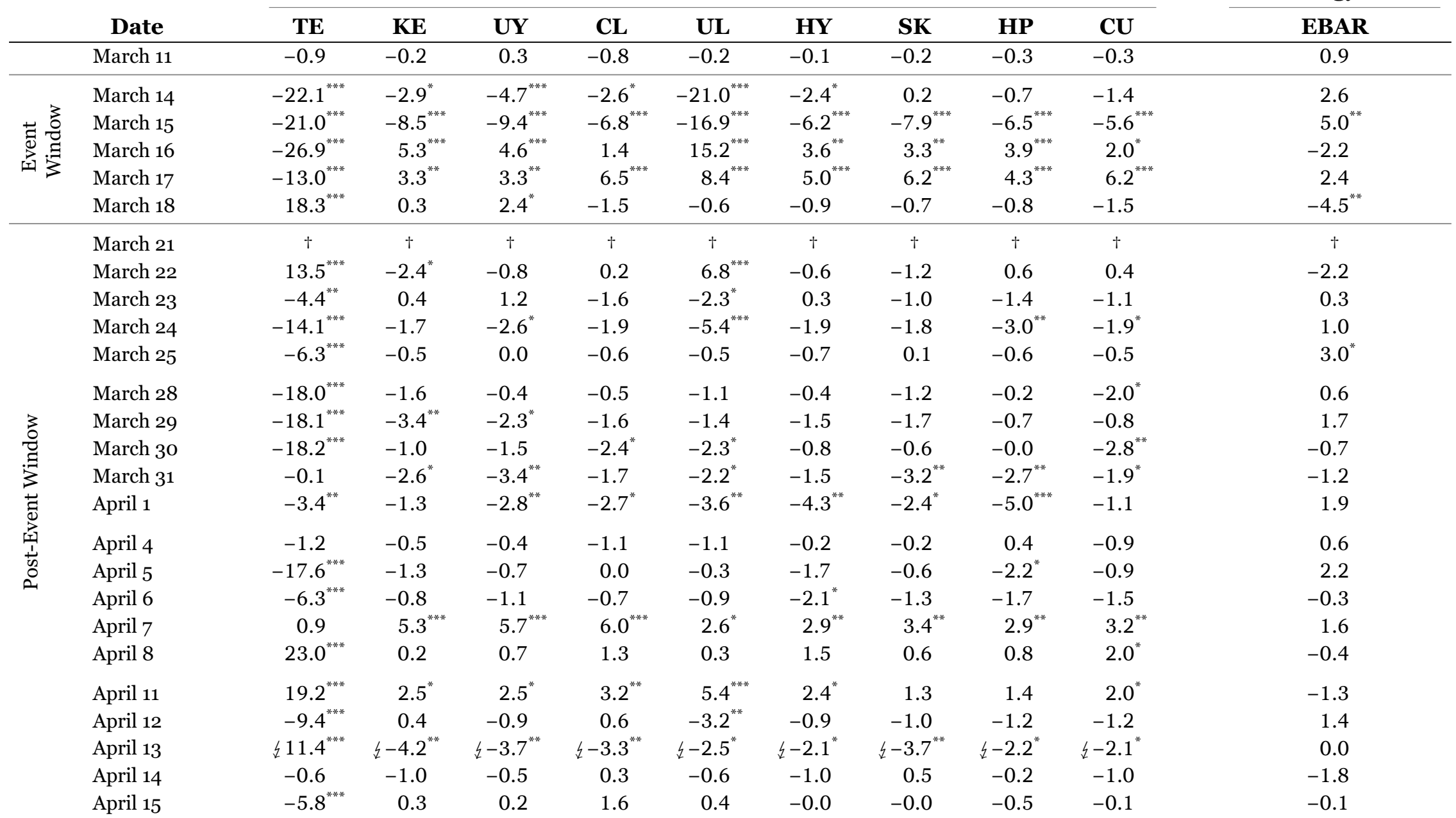

All values are given in percentage. The nuclear companies are listed in descending order by their megawatt capacities. *, **, *** denote significant abnormal returns at a $10 \%, 5 \%$, and $1 \%$ level, respectively. The p-values (not reported separately) are calculated using a MVRM and the HWZ bootstrap method as described in Hein and Westfall (2004) with 10o,ooo bootstrap samples each. Returns on days exhibiting possible confounding events according to Table B-2 are marked with \&, holidays are marked with †. 
Table B-5: Daily abnormal returns of nuclear and alternative energy companies in the USA

Nuclear Stocks

Alternative Energy Stocks Date EXC ETR D NEE DUK FE PGN SO PEG PCG EIX PPL AEP CEG XEL AEE PNW NRG DTE ASTI CSIQ HEV ENER HOKU PLUG RZTI

\begin{tabular}{|c|c|c|c|c|c|c|c|c|c|c|c|c|c|c|c|c|c|c|c|c|c|c|c|c|c|}
\hline \multirow{2}{*}{$\begin{array}{l}\text { Date } \\
\text { Mr } 11\end{array}$} & \multirow{2}{*}{\multicolumn{2}{|c|}{$\begin{array}{ll}\mathbf{E X C} \mathbf{E T} \\
-0.3-0.6\end{array}$}} & \multirow{2}{*}{$\begin{array}{c}\text { D } \\
-1.0\end{array}$} & \multirow{2}{*}{\multicolumn{2}{|c|}{$\begin{array}{l}\text { NEE DUF } \\
-0.2 \quad 0.0\end{array}$}} & \multirow{2}{*}{$\frac{-}{-0.4-0.5}$} & \multirow{2}{*}{\multicolumn{2}{|c|}{$\begin{array}{ll}\text { SO PEG } \\
-0.9 \quad 0.2\end{array}$}} & & & \multirow[b]{2}{*}{.3} & \multirow[b]{2}{*}{-0.4} & \multirow{2}{*}{\multicolumn{2}{|c|}{$\frac{\text { CEG XEL }}{3.5^{*}-0.1}$}} & & & & & & & & & & \multirow[b]{2}{*}{.0} \\
\hline & & & & & & & & & -1.2 & 0.2 & & & & & -0.5 & 0.4 & 1.6 & 0.3 & -3.2 & -2.6 & 7.0 & $y-22.4^{* * x}$ & -0.4 & -4.2 & \\
\hline Mr 14 & -0.3 & $-4.6^{* * *}$ & -0.6 & -0.9 & -1.2 & $-0.0-0.6$ & -1.5 & $-2.4^{*}$ & ${ }^{*}-2.8^{* * *}$ & $-2.3^{*}$ & 0.3 & -1.0 & -0.4 & -1.1 & -1.2 & 0.2 & 2.5 & -0.8 & 5.1 & -1.6 & $-7.4^{*}$ & 0.8 & 5.3 & -3.7 & -8.2 \\
\hline Mr 15 & $2.8^{*}$ & -1.7 & -0.4 & -1.7 & -1.0 & $-2.1-1.1$ & -1.3 & -0.5 & $-2.7^{* *}$ & ${ }^{*}-1.9$ & -1.9 & -0.5 & $-3.1^{*}$ & ${ }^{*}-1.0$ & -0.6 & $-2.2^{*}$ & 1.0 & 0.0 & $12.0^{* *}$ & $12.3^{* *}$ & -1.6 & -1.9 & 5.7 & -1.1 & 1.2 \\
\hline Ir 16 & 1.4 & -1.1 & -0.9 & -0.5 & -0.2 & $0.1-0.2$ & 0.5 & -0.7 & 0.1 & 0.8 & 0.7 & -0.4 & -0.7 & 0.1 & 1.2 & -0.1 & 2.7 & 0.4 & -6.5 & -4.6 & 2.8 & -2.5 & 2.7 & 1.3 & $16.6^{* * *}$ \\
\hline Mr 17 & -0.6 & $-2.8^{*}$ & -1.2 & -0.7 & -1.1 & $-1.2-2.1^{*}$ & -0.5 & -0.7 & -0.4 & -0.7 & -0.7 & $-2.9^{* *}$ & -1.0 & -0.1 & -0.4 & -1.5 & -0.0 & $-1.9^{*}$ & -5.4 & -0.7 & -2.3 & $-8.7^{*}$ & -6.4 & -0.2 & -3.6 \\
\hline Mr 18 & -0.4 & 0.4 & 0.4 & -0.2 & 0.1 & $-0.0 \quad 0.4$ & 0.3 & -0.1 & 0.9 & 0.1 & 0.6 & 0.6 & 1.3 & -0.5 & 0.5 & -0.4 & 0.8 & -0.6 & -1.7 & -2.7 & -4.9 & 4.5 & 1.8 & 2.0 & -1.7 \\
\hline r 21 & -0.4 & -0.9 & 0.6 & 0.6 & -0.5 & $-0.5 \quad 0.1$ & 3. & -0.2 & 0.6 & 0.6 & - & -0.3 & 0.2 & 0.0 & 0.4 & 0.1 & .2 & 0.2 & 1.0 & - & 0.6 & .0 & 2. & 0.7 & $-12.0^{*}$ \\
\hline Mr 22 & 2.1 & $2.2^{*}$ & 0.2 & 0.6 & 0.5 & $0.5 \quad 0.7$ & 0.1 & 1.2 & 0.3 & 0.7 & -0.5 & 0.6 & -0.2 & -0.8 & -0.7 & -0.7 & 1.7 & -0 & 1 & 2.1 & 1.4 & 1.0 & -0.7 & 2.8 & 1.0 \\
\hline Mr 23 & -0.6 & -0.1 & -1.0 & -0.8 & 0.1 & $-0.5 \quad 0.1$ & 0.0 & 0.2 & -0.7 & -0.3 & -0.6 & 0.8 & 1.2 & -0.5 & 0.4 & 0.3 & -0.5 & -0 & -0.7 & 1.0 & -2.7 & -0.6 & -1.8 & -2.4 & -2.8 \\
\hline Mr 24 & 0.8 & -0.8 & -0.1 & -0.4 & -0.5 & $-1.3-0.2$ & -0.5 & -1.0 & -0.7 & -0.3 & -0.6 & 0 & -1.0 & -0.4 & -0.1 & 0.1 & -1.0 & - & -1 & -2.4 & -0.9 & 0.9 & 2. & -1.0 & 0.8 \\
\hline Mr 25 & -1.2 & -0.7 & 0.1 & -0.0 & -0.4 & $-0.2 \quad 0.1$ & -0.0 & -0.4 & 0.4 & -0.6 & 0.3 & -0.5 & -0.4 & -0.0 & -0.1 & -0.1 & 0.6 & -0. & -2.6 & -1.7 & 1.5 & 2.0 & 2. & -1.5 & -3.1 \\
\hline Mr 28 & -0.8 & 01 & -0.6 & -0.6 & 0.2 & $-0.7 \quad 0.4$ & -0.1 & -0.2 & -0.1 & -1.2 & -0.1 & 0 . & -0.6 & -0.4 & 0.0 & -0.2 & -0.0 & -0.5 & 1.8 & 2.8 & 1.0 & 2.7 & 3.3 & -0.7 & 5.0 \\
\hline Mr 29 & 0.8 & 0.6 & 0.2 & 1.0 & 0.6 & $-0.0 \quad 0.5$ & -0.0 & 0.4 & -1.2 & 0.1 & 06 & 0 & -0.1 & 0.4 & 0.7 & -0 & 0.6 & 0 & $1^{* *}$ & -0.6 & 4.6 & -0.5 & -4.6 & $\left\{12.3^{* *}\right.$ & -5.2 \\
\hline $\mathrm{Mr} 30$ & 1.2 & 0.6 & 1.0 & 0.0 & 0.3 & $1.4 \quad 0.5$ & 0.8 & 0.7 & 0 & 0.0 & 0 & 0 & 1.5 & 0.8 & 1.0 & 1. & 0. & 1. & -3 & -0.4 & -3.9 & 4.2 & 0.1 & 0.4 & -2.0 \\
\hline $\mathrm{Mr}_{31}$ & -0.2 & -0.8 & -0.8 & 0.5 & 0.1 & $0.3-0.3$ & 0.2 & -0.2 & 0.7 & 0.2 & 0.9 & -0.8 & -0.7 & -0.0 & -0.3 & 0.1 & -1.0 & 0. & -2.4 & -2.8 & -3.7 & -6.1 & -2.4 & 1.4 & 2.1 \\
\hline Ap 1 & -0.8 & 0.1 & -0.5 & 0.9 & 1.0 & $-0.1 \quad 0.8$ & 0.1 & -0.6 & 0.2 & 0.7 & 1.1 & 0.6 & 0.4 & 0.4 & -0.1 & 0.7 & -0.2 & 0.3 & $\xi-25.9^{* * * *}$ & ${ }^{* *}-2.8$ & -0.4 & 2.8 & -0.3 & -1.0 & -1.7 \\
\hline Ap 4 & -0.2 & -0.3 & 0.5 & 0.5 & -0.2 & $-0.3 \quad 0.2$ & 0 & .9 & -0.0 & -0.4 & 0.5 & -0.2 & -0.6 & 0.3 & 0.8 & -0.2 & -1.2 & 0.0 & $-23.1^{* * * *}$ & ${ }^{* *}-1.2$ & -1.4 & -5.7 & -1.1 & $-12.0^{* * *}$ & -1.6 \\
\hline Ap 5 & & -0.9 & -0.4 & 0.0 & 0.0 & $-1.0-0.1$ & -0 & & -0.1 & -0.0 & -1.1 & -0.4 & 0.6 & -0.6 & 0.1 & -0.8 & -1.3 & & 6 & -00 & -0.2 & 6.2 & 0.9 & 1.4 & $-14.8^{* * *}$ \\
\hline Ap 6 & 0.6 & 0.8 & 0.6 & 0.6 & 0.9 & $\begin{array}{ll}1.5 & 0.9\end{array}$ & 1 & $2.5^{*}$ & 1.4 & 0.5 & 0.2 & 0 . & 1.2 & 0.6 & 1.4 & 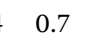 & 1. & & -3.2 & -0.2 & 1.0 & 0.4 & -1.1 & 3.0 & 々 $-31.5^{* * * *}$ \\
\hline Ap 7 & -0.5 & -0.7 & -0.1 & -0.8 & -0.9 & $-0.1-2.1^{*}$ & 0.2 & -0.5 & -0.5 & -0.2 & 0.7 & -0.2 & $3.3^{*}$ & -0.7 & 0.2 & -0.3 & 2.5 & -0.2 & -0.0 & -0.5 & -1.0 & 4.9 & 0.4 & -1.8 & $21.6^{* * *}$ \\
\hline Ap 8 & -0.3 & -0.5 & -0.2 & 0.0 & 0.3 & $0.0 \quad 0.0$ & -0.8 & -0.3 & -0.2 & 1.2 & 1.0 & -0.3 & 1.9 & -0.4 & -0.8 & 0.1 & -0.9 & -0.5 & -3.4 & -1.6 & -1.3 & -1.5 & 1.9 & 2.5 & 2.6 \\
\hline Ap 11 & -1.4 & -1.4 & $1.9^{*}$ & -1.5 & -1.3 & $-1.0-1.4$ & -1.7 & 2.1 & & 12 & -0 & -1 & 0.7 & -1.5 & -1.1 & -1 & -0.0 & 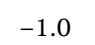 & & -0 & 2 & -0 . & 0 & 17 & 19 \\
\hline 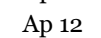 & 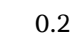 & 0.2 & -0.6 & 0.3 & -0.6 & $1.1-0.3$ & -0.6 & 0.5 & & $\left\{3.6^{* *}\right.$ & * $45.2^{*}$ & -0.2 & -0.1 & ? & 0.8 & -0 & 0.2 & - & & 1.3 & -5.7 & 0.1 & 1.9 & -3 & -5.7 \\
\hline Ap 13 & 0 & 0.0 & -0.4 & -0.6 & 0.3 & $1.7 \quad 0.5$ & 0.0 & 0.9 & -0.0 & 0.4 & -0.5 & 0.8 & 0.4 & 0.2 & -0.5 & -0.2 & -0.4 & 0.0 & 4.4 & 1.0 & 5.8 & 5.9 & 1.1 & -4.1 & -0.1 \\
\hline Ap 14 & 0 & 0.5 & 1.1 & 0.3 & 0.7 & 1.10 .9 & 0.7 & -0.2 & 0.5 & 0.0 & -0.2 & 0.8 & 0.3 & 0.6 & 0.6 & 1. & 0.1 & -0.2 & -2.1 & -2.3 & -1.7 & -4.3 & 0.7 & 1.8 & -3.7 \\
\hline Ap 15 & 0.9 & 1.0 & 0.8 & -0.3 & 0.7 & $\begin{array}{ll}0.6 & 0.7\end{array}$ & 1.2 & 0.9 & 1.7 & 1.1 & 0.8 & 0.6 & 1.1 & 1.4 & 1.9 & 0.8 & 1.1 & 1.7 & -3.2 & -2.5 & -1.8 & 0.2 & -1.0 & -4.9 & $-10.0^{*}$ \\
\hline
\end{tabular}

All values are given in percentage. The nuclear companies are listed in descending order by their megawatt capacities. ${ }^{*}, * *, * *$ denote significant abnormal returns at a $10 \%, 5 \%$, and $1 \%$ level, respectively. The p-values (not reported separately) are calculated using a MVRM and the HWZ bootstrap method as described in Hein and Westfall (2004) with

10o,ooo bootstrap samples each. Returns on days exhibiting possible confounding events according to Table B-2 are marked with $\downarrow$, holidays are marked with †. 
Table B-6: Median daily ARs and mean daily CARs of nuclear and alternative energy companies

Nuclear Stocks

Alternative Energy Stocks

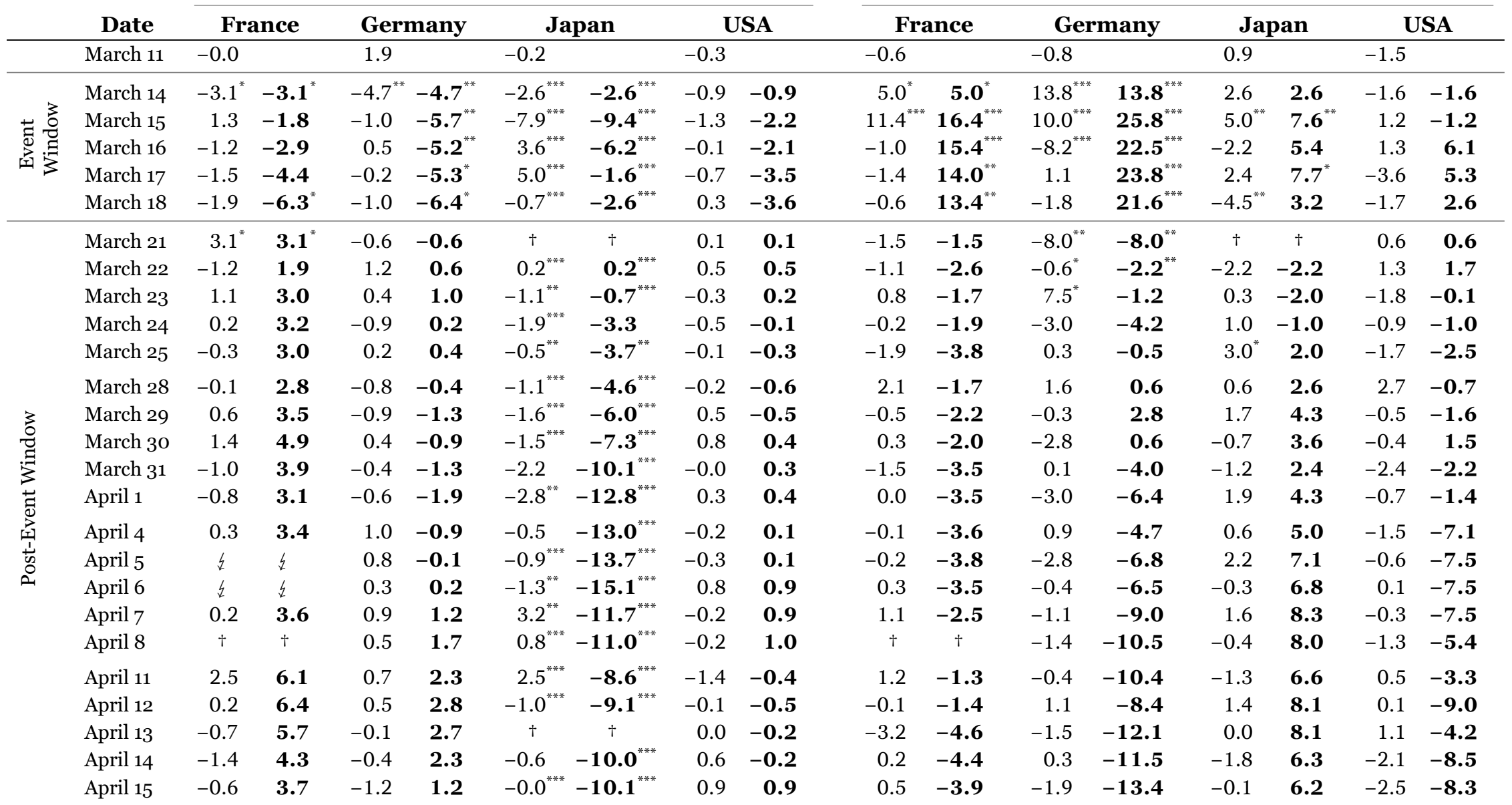

Median daily abnormal returns (in regular letters) and median daily cumulative abnormal returns (in bold letters) of nuclear and alternative energy companies in the respective markets. All values are given in percentage. ${ }^{*},{ }^{* *},{ }^{* * *}$ denote joint significant (cumulative) abnormal returns at a $10 \%$, $5 \%$, and $1 \%$ level, respectively, corresponding to the hypotheses given in section 2.3. The p-values (not reported separately) are calculated using a MVRM and the HWZ bootstrap method as described in Hein and Westfall (2004) with 10o,ooo

bootstrap samples each. Confounding events according to Table B-2 are excluded from the analysis and marked with 4 , holidays are marked with $\dagger$. 


\section{Acknowledgments}

We thank Engelbert Dockner (the department editor), two anonymous referees, Gregor Dorfleitner, and the brown bag seminar participants at University of Regensburg for helpful comments and discussion.

\section{References}

Acharya, Sankarshan (1993): Value of Latent Information: Alternative Event Study Methods, Journal of Finance, 48 (1): 363-385.

Aktar, Ismail (2005): A Comparison of the Effects of the Chernobyl and Three Mile Island Nuclear Accidents on the U.S. Electric Utility Industry, Sosyoekonomi, 2005 (2): 11-34.

Barrett, W. Brian, Andrea J. Heuson, and Robert W. Kolb (1986): The Effect of Three Mile Island on Utility Bond Risk Premia: A Note, Journal of Finance, 41 (1): 255-261.

Binder, John J. (1985): On the Use of the Multivariate Regression Model in Event Studies, Journal of Accounting Research, 23 (1): $370-383$.

Binder, John J. (1998): The Event Study Methodology Since 1969, Review of Quantitative Finance and Accounting, 11 (2): 111-137.

Bowen, Robert M., Richard P. Castanias, and Lane A. Daley (1983): Intra-Industry Effects of the Accident at Three Mile Island, Journal of Financial and Quantitative Analysis, 18 (1): 87-111.

Dissanaike, Gishan and Alexandre Le Fur (2003): On the Use of the Log CAR Measure in Event Studies, Journal of Business Finance \& Accounting, 30 (7-8): 1165-1170.

Fama, Eugene F., Lawrence Fisher, Michael C. Jensen, and Richard Roll (1969): The Adjustment of Stock Prices to New Information, International Economic Review, 10 (1): 1-21.

Fama, Eugene F. and Kenneth R. French (1993): Common Risk Factors in the Returns on Stocks and Bonds, Journal of Financial Economics, 33 (1): 3-56.

Fama, Eugene F. and Kenneth R. French (1995): Size and Book-to-Market Factors in Earnings and Returns, Journal of Finance, 50 (1): 131-155.

Fields, M. Andrew and Vahan Janjigian (1989): The Effect of Chernobyl on Electric-Utility Stock Prices, Journal of Business Research, 18 (1): 81-87.

Foster, George (1980): Accounting Policy Decisions and Capital Market Research, Journal of Accounting and Economics, 2 (1): 29-62.

Harrington, Scott E. and David G. Shrider (2007): All Events Induce Variance: Analyzing Abnormal Returns when Effects Vary Across Firms, Journal of Financial and Quantitative Analysis, 42 (1): 229-256.
Hein, Scott E. and Peter Westfall (2004): Improving Tests of Abnormal Returns by Bootstrapping the Multivariate Regression Model with Event Parameters, Journal of Financial Econometrics, 2 (3): 451-471.

Hill, Joanne and Thomas Schneeweis (1983): The Effect of Three Mile Island on Electric Utility Stock Prices: A Note, Journal of Finance, 38 (4): 1285-1292.

International Atomic Energy Agency (2010): Nuclear Power Reactors in the World, http: // www-pub.iaea.org / MTCD / publications/PDF/iaea-rds-2-30_web.pdf (Access date: 201104-07).

Kalra, Rajiv, Glenn V. Henderson jr., and Gary A. Raines (1993): Effects of the Chernobyl Nuclear Accident on Utility Share Prices, Quarterly Journal of Business and Economics, 32 (2): 52-77.

MacKinlay, A. Craig (1997): Event Studies in Economics and Finance, Journal of Economic Literature, 35 (1): 13-39.

McWilliams, Abagail and Donald Siegel (1997): Event Studies in Management Research: Theoretical and Empirical Issues, Academy of Management Journal, 40 (3): 626-657.

Nuclear Energy Institute (2011): U.S. Reactor Ownership and Management, http: //www.nei.org / filefolder / US_Nuclear_ Power_Plant_Operators_Owners_and_Holding_Companies. xls (Access date: 2011-04-20).

\section{Biographies}

Robert Ferstl received an M. Sc. degree in economics and a doctoral degree in economics from the Vienna University of Economics and Business, Austria, in 2004 and 2008, respectively. He is currently an analyst at the Off-Site Banking Analysis and Strategy Division of the Oesterreichische Nationalbank.

Sebastian Utz is a research assistant at the Department of Finance, University of Regensburg and a student of the Konrad-Adenauer-Stiftung postgraduate scholarship. He received a Diploma in mathematics from the University of Augsburg in 2009.

Maximilian Wimmer is a research fellow at the Department of Finance, University of Regensburg. He received an M. Sc. in mathematics from Iowa State University in 2006, a Diploma in business mathematics from the University of Augsburg in 2007, and a doctoral degree in business administration from the University of Regensburg in 2010. 